\title{
A judicialização da saúde no Brasil e na Colômbia: uma discussão à luz do novo constitucionalismo latino-americano'
}

\section{Judicialization of health in Brazil and Colombia: a discussion in light of the new Latin American constitutionalism}

\author{
Luciana Souza d'Ávilaa,b \\ (i) https://orcid.org/0000-0001-6998-4587 \\ E-mail: lucianasdı4mळgmail.com \\ Eli Iola Gurgel Andrade $e^{b, c}$ \\ (D) https://orcid.org/0000-0002-0206-2462 \\ E-mail: iolaळmedicina.ufmg.br

\section{Fernando Mussa Abujamra Aith ${ }^{d}$} \\ (D) https://orcid.org/0000-0003-1971-9130 \\ E-mail: fernando.aithळusp.br
}

aEscola de Saúde Pública do Estado de Minas Gerais. Superintendência de Educação e Pesquisa em Saúde. Coordenação de Promoção, Cuidado e Vigilância em Saúde. Belo Horizonte, MG, Brasil.

bUniversidade Federal de Minas Gerais. Faculdade de Medicina. Pós-Graduação em Saúde Pública. Belo Horizonte, MG, Brasil.

'Universidade Federal de Minas Gerais. Faculdade de Medicina. Departamento de Medicina Preventiva e Social. Belo Horizonte, MG, Brasil.

¿Universidade de São Paulo. Faculdade de Saúde Pública. Departamento de Política, Gestão e Saúde. São Paulo, SP, Brasil.

\section{Correspondência}

Luciana Souza d'Ávila

Rua Uberaba, 780, $3^{\circ}$ andar. Belo Horizonte, MG, Brasil. CEP 30180-080.

\section{Resumo}

Este artigo busca analisar a judicialização da saúde no Brasil e na Colômbia à luz do novo constitucionalismo latino-americano (NCLA), corrente conceitual adotada na região que rompe com os modelos constitucionais europeus e norteamericanos clássicos. No Brasil, a Constituição de 1988 veio em resposta a um longo período de governos militares e, na Colômbia, a Constituição de 1991 surgiu em um contexto de abusos de direitos humanos e altos níveis de violência. O NCLA se materializa a partir dessas novas Cartas Políticas e se sustenta no incremento das formas de participação e na ampliação do papel do Judiciário e dos direitos, como o da saúde. Entretanto, as constituições que trazem uma ampla carta de direitos não conseguiram enfrentar as políticas orientadas para o mercado e a privatização dos serviços de saúde, colocando em xeque a efetivação do direito à saúde e levando ao aumento das ações judiciais. Nesse cenário emerge o protagonismo do Judiciário, fortalecido pelas novas constituições, como poder estatal capaz de concretizar um direito previsto, mas marginalizado. A identificação das necessidades de saúde e reivindicações de segmentos sociais apresenta-se como princípio basilar nesse processo e sinaliza o resgate do NCLA para a efetivação do direito à saúde por meio do litígio estrutural.

Palavras-chave: Judicialização da Saúde; Novo Constitucionalismo; América Latina; Brasil; Colômbia.

\footnotetext{
1 Estudo financiado pela Fundação de Amparo à Pesquisa de Minas Gerais (Fapemig) por meio de concessão de bolsa de doutorado à primeira autora do artigo.
} 


\section{Introdução}

This study aims to analyze the judicialization of health in Brazil and Colombia in light of the new Latin American Constitutionalism (NLC), a conceptual framework adopted in the region that breaks with the European and North American classic constitutional models. In Brazil, the Constitution of 1988 came as a response to a long period of military governments, and in Colombia the Constitution of 1991 emerged in a context of human rights abuses and high level of violence. The NLC is materialized from these new political letters and based on increasing forms of participation and expansion of the role of the Judiciary and people's rights, including health. However, the constitutions that brought a broad bill of rights have failed to face market-oriented policies and privatization of health services, thus limiting the realization of the right to health to increasing litigation. In this scenario, the role of the Judiciary, which has been strengthened by the new constitutions, gained importance as the branch capable of realizing a provided but precluded right. The identification of health needs and claims by social segments is presented as a basic principle in this process and indicates the rescue of the NLC for the realization of the right to health through structural litigation.

Keywords: Judicialization of Health; New Constitutionalism; Latin America; Brazil; Colombia.
Este artigo busca analisar a judicialização da saúde no Brasil e na Colômbia à luz do novo constitucionalismo latino-americano (NCLA), uma corrente conceitual adotada na região a partir do final dos anos 1980 que busca romper com os modelos constitucionais europeus e norteamericanos clássicos e acolhe as demandas culturais, sociais, políticas e democráticas dos povos (Bragato; Castilho, 2014). Nesse contexto, o resgate dos princípios do NCLA pode contribuir para se repensar o processo de litigância em saúde nos dois países, com vistas à plena efetivação do direito à saúde.

A Colômbia, assim como o Brasil, apresenta desde os anos 1990 um aumento expressivo de ações judiciais envolvendo esse direito, fenômeno que tem sido denominado "judicialização da saúde". A perda de legitimidade do sistema sanitário se reflete no crescente número de ações de tutela, sendo que em 2018 foram interpostas 207.734 ações devido à violação do direito à saúde (Colômbia, 2019). No caso do Brasil, dados do Conselho Nacional de Justiça (CNJ) revelam um aumento significativo do número de demandas ao se analisar sua evolução, passando de 1.778.269 ações em 2018 para 2.228.531 em 2019 (Schulze, 2019).

A judicialização da saúde vem sendo estudada sob perspectivas diversas no contexto brasileiro, as quais enfocam as características das ações, os efeitos para o sistema de saúde e os aspectos relacionados à conduta dos juízes em suas decisões. $\mathrm{O}$ acesso ao Judiciário é direito constitucional e mecanismo de exercício da cidadania, mas há críticas sobre seu impacto, pois pode gerar consequências orçamentárias, como o desvio de recursos de políticas prioritárias (Ferraz, 2011; Vieira, 2008).

Os críticos da judicialização ainda ressaltam o predomínio dos pleitos individuais, a desigualdade no acesso à justiça, o não respeito à separação de poderes e a influência da indústria farmacêutica. Por outro lado, tem-se a percepção de que, ao mesmo tempo que decisões judiciais permitem o acesso a tratamentos não incorporados ao sistema de saúde, podem sinalizar necessidades individuais e coletivas não atendidas, tornando-se importante instrumento de avaliação para a política pública (Andrade et al., 2008; 
Campos Neto; Gonçalves; Andrade, 2018; Fleury, 2012; Gomes et al., 2014; Machado; Dain, 2012). Na Colômbia, a judicialização é tida como responsável pelos avanços dos direitos sociais ao garantir a aplicabilidade da Constituição e a proteção da dignidade e da vida de minorias e das vítimas da violência que assola o país (Uprimny; García-Villegas, 2002).

Vale ressaltar que a comparação entre Brasil e Colômbia se mostra estratégica, pois, além da convergência em relação à relevância da judicialização para o acesso à saúde, ambos os países tiveram suas atuais Constituições promulgadas no mesmo momento histórico (Brasil em 1988, Colômbia em 1991), a partir de um processo de ruptura democrática contra um contexto de abusos de direitos humanos e desigualdades sociais profundas. Paralelamente, apesar de os dois sistemas de saúde apresentarem diferenças, particularmente em relação à abrangência do direito à saúde, ao financiamento e à relação público-privada (Almeida, 1999; Cebes, 2014; Gargarella, 2017; Holst; Giovanella; Andrade, 2016; Vélez, 2016), há indícios de que as mudanças impostas ao sistema brasileiro vêm levando à sua aproximação.

Em termos metodológicos, a análise comparativa de fenômenos políticos funciona como dispositivo teórico e ferramenta de controle de resultados (Bulcourf; Cardozo, 20o8), sendo vantajosa a comparação de países com conjunturas históricas semelhantes em aspectos importantes para se compreender os processos dentro de cada contexto (Evans; Rueschemeyer; Skocpol, 1985). Para tanto, foi realizada revisão narrativa da literatura que incluiu artigos, livros, documentos legais e informes estatísticos disponíveis nas principais bases de dados de literatura científica e oficiais dos países, como a Scientific Electronic Library Online (SciELO), o CNJ, no Brasil, e a Defensoría del Pueblo, na Colômbia. A análise envolveu o diálogo entre a judicialização da saúde e as bases teóricas do NCLA, buscando-se um ponto de vista alternativo para esse debate a partir de suas três características principais: a expansão nas formas de participação; a ampliação de direitos e o fortalecimento do poder
Judiciário. Não foi estabelecida distinção entre judicialização e ativismo judicial, ${ }^{2}$ conceitos que serão discutidos como parte do mesmo movimento.

\section{novo constitucionalismo latino- americano no Brasil e na Colômbia}

\section{Bases teóricas}

As constituições não são apenas matrizes de processos políticos, mas síntese do embate de forças e de lutas sociais, relacionadas ao momento histórico do desenvolvimento das coletividades (Wolkmer, 2010). Na América Latina, a história do constitucionalismo foi marcada pela disputa entre conservadores e liberais, os quais se uniram ("Constitucionalismo de Fusão") na metade do século XIX para enfrentar os ideais republicanos trazidos das revoluções europeias, instituindo as principais constituições da região (Gargarella, 2013; Gargarella; Courtis, 2009). Essas constituições surgiram de processos pouco democráticos, conduzidos pelas elites (Pastor; Dalmau, 2010) e, apesar de o liberalismo ter defendido a adoção de direitos de forma universalista, estes estavam relacionados a direitos de propriedade e distribuídos de maneira desigual (Gargarella; Courtis; 2009).

No final daquele século, um novo regime buscou o crescimento econômico por meio de uma dura disciplina imposta à população (regimes de "Ordem e Progresso"), levando a conflitos sociais e a governos autoritários. 0 constitucionalismo foi então pautado, com exceções, por sistemas legais excludentes, limites de direitos políticos e concentração de poder no Executivo, com uso de poderes coercitivos. A partir dos anos 1970, a América Latina foi impactada por uma crise política e por graves abusos dos direitos humanos, além de ter sofrido uma crise social e econômica relacionada a programas de ajuste fiscal (Gargarella, 2013). Entre 1980 e 1990, em meio a manifestações da sociedade civil, as novas constituições latino-americanas começaram a se materializar, em grande medida, como resultado dos

\footnotetext{
2. Para Streck (2016), enquanto o ativismo judicial está relacionado à visão pessoal e à vontade dos juízes, a judicialização é contingencial e seu efeito - positivo ou negativo - depende do grau em que é observada.
} 
processos de redemocratização de diversos países, tendo como pilares a participação nos processos constituintes e o clamor por mudanças sociais. A primeira constituição desse movimento foi a do Brasil (1988), ${ }^{3}$ seguida pela da Colômbia (1991), do Paraguai (1992), do Peru (1993), da Venezuela (1999) e as Constituições plurinacionais do Equador (2008) e da Bolívia (2009) (Avritzer, 2017; Gargarella, 2013, 2017; Gargarella; Courtis; 2009).

No caso do Brasil, a Constituição de 1988 (CF/88) sofreu influência direta da luta pela derrubada da ditadura militar, uma vez que surgiu para se contrapor à Constituição autoritária de 1967 (Gargarella, 2017). Os direitos civis foram restaurados e ampliados e a nova Constituição buscou corrigir os problemas e abusos da Carta anterior, criando barreiras contra violações dos direitos humanos e ações antidemocráticas, restaurando o voto direto e secreto, introduzindo mudanças na organização dos poderes e incluindo um rol inédito de direitos sociais (Avritzer; Marona, 2014; Gargarella, 2013, 2017). Além disso, a CF/88 consagrou fundamentos pluralistas em diversos campos, tais como o religioso, o filosófico, o político e o cultural (Wolkmer, 2010). Embora os movimentos sociais e políticos tenham exigido uma Assembleia Constituinte indicada pelo povo, o Congresso convocado foi composto por parlamentares eleitos em 1986, pertencentes majoritariamente aos setores moderados (Pisarello, 2012, 2014), o que pode explicar o caráter misto da Constituição.

A Colômbia, apesar de ter longa tradição de governos civis e eleições regulares, enfrentava um período de altos níveis de violência, violações de direitos humanos e grave desigualdade social (Uprimny, 2004; Uprimny; García-Villegas, 2002). O ápice da crise ocorreu quando o Estado perdeu o controle de várias partes do território devido à presença de guerrilhas, grupos paramilitares e do tráfico de drogas, culminando com a ocupação da Suprema Corte pelo grupo guerrilheiro Movimento 19 de Abril (Gargarella, 2013). Em 1990, a partir da demanda de diversos setores da sociedade pela ampliação democrática e pelo estabelecimento de um novo contrato social, o então presidente César Gaviria convocou uma Constituinte ${ }^{4}$ que contou com a participação de grupos antes marginalizados, como guerrilheiros desmobilizados, indígenas e minorias religiosas (Díaz, 2010; Uprimny, 2004, 2006; Uprimny; García-Villegas, 2002). 0 resultado foi uma Constituição que promove a dignidade humana, a equidade e a participação democrática (Iturralde, 2013).

O NCLA se origina a partir dessas novas Cartas Políticas, e representa uma ressignificação do constitucionalismo clássico, na medida em que inova fundamentos e práticas constitucionais por meio da ampliação de direitos e da participação (Avritzer, 2017), além de legitimar e representar as lutas democráticas e emancipatórias do povo latinoamericano. Essa perspectiva traz a Constituição como espaço para expressar a soberania popular (poder constituinte) sobre a configuração do Estado, superando a visão da Constituição como mera limitadora do poder constituído (Pastor; Dalmau, 2010). Nesse sentido, as novas constituições latino-americanas desvelam tensões próprias da cidadania, como a relação entre universalidade e igualdade, particularidade e diferença, envolvendo três características basilares: a ampliação de direitos, incluindo à saúde; a reconfiguração do papel do Judiciário; e o incremento das formas de participação nas diversas instâncias de poder ${ }^{5}$ (Avritzer, 2017; Avritzer; Marona, 2014). No entanto, embora a previsão e a consagração constitucionais de direitos fundamentais e sociais tenham

3 Apesar de alguns autores considerarem que as bases do NCLA podem ser identificadas somente a partir da Constituição Colombiana de 1991 (Nárdiz, 2016; Pastor; Dalmau, 2010), considera-se que a Carta Constitucional brasileira de 1988 traz avanços que justificam seu enquadramento na perspectiva do NCLA, tais como a instituição da participação popular, a característica pluralista e a inclusão de mecanismos de valorização e proteção multicultural (Avritzer, 2017; Gargarella, 2017; Wolkmer, 2010).

4 A Assembleia Constituinte foi convocada por um mecanismo controverso, o decreto de estado de sítio, para cumprir o propósito reformista, o qual foi ratificado pela Corte Suprema de Justiça (Díaz, 2010).

5 As duas primeiras características, apesar de presentes no neoconstitucionalismo, se apresentam de forma peculiar na América Latina, onde a busca pela democracia é uma questão prioritária. Além disso, o NCLA compartilha com o neoconstitucionalismo a dimensão positiva da Constituição e sua centralidade no ordenamento jurídico, tanto em seu desenvolvimento como em sua interpretação (Grijalva, 2017; Pastor; Dalmau, 2010). 
avançado, de forma contraditória a estrutura vertical de poder com concentração nas mãos do presidente se manteve (Gargarella, 2013, 2017; Gargarella; Courtis, 2009).

\section{A ampliação de direitos no Brasil e na Colômbia e os desafios para a efetivação do direito à saúde}

No que se refere à ampliação de direitos, foram reconhecidos os à diversidade, à terra e à preservação do patrimônio cultural das comunidades tradicionais, tanto na constituição brasileira (ainda que de forma incipiente) quanto na colombiana, a qual avançou mais nesse aspecto (Avritzer, 2017). Além disso, o rol de direitos sociais, econômicos e culturais - entre eles o direito ao lazer, à alimentação e à moradia adequadas, à educação e à saúde - foi expandido, com ampla interpretação dos seus destinatários, como idosos, crianças e incapacitados, estabelecendo nova ruptura com o constitucionalismo clássico, o qual institui direitos de forma genérica, sem se preocupar com sua individualização ou coletivização (Courtis, 2006; Gargarella; Courtis, 2009; Pastor; Dalmau, 2010).

O direito à saúde, especificamente, foi reconhecido no Brasil como um "direito de todos e dever do Estado” (Brasil, 1988, art. 196), constando no artigo $6^{\circ} \mathrm{da} \mathrm{CF} / 88$ como um direito social e no artigo 194 como parte do sistema de seguridade social. Os artigos 196 a 200 estabelecem questões gerais do sistema sanitário, abarcando seu financiamento e a organização da assistência (Brasil, 1988). Na constituição colombiana, o artigo 49 prevê o direito à saúde para todas as pessoas, garantindo "acesso aos serviços de promoção, proteção e recuperação da saúde”, e estabelecendo como dever de todos "buscar o cuidado integral de sua saúde e de sua comunidade" (Colômbia, 1991, tradução nossa).

0 direito à saúde no Brasil se materializou a partir da criação do Sistema Único de Saúde (SUS), o qual representou um grande avanço para a população (Moutinho; Dallari, 2019), mas há ainda desafios a serem enfrentados para sua efetivação. Apesar de a CF/88 trazer esse direito como universal, o próprio texto constitucional apresenta uma contradição ao permitir que a atenção à saúde seja realizada pela iniciativa privada, transformando os cidadãos em consumidores (Cebes, 2014). Há ainda desafios relacionados ao próprio sistema e a aspectos estruturais da sociedade que interferem na realização dos direitos sociais, como a desigualdade e a não implementação de políticas públicas redistributivas e inclusivas (Garbois; Vargas; Cunha, 2008; Paula et al., 2009; Silva, 2013). Tais desafios estão presentes no contexto brasileiro atual, uma vez que as políticas de austeridade e os ataques aos direitos e às políticas sociais ameaçam seriamente o financiamento, o acesso e a qualidade da atenção (Costa; Rizzotto, 2017; Holst; Giovanella; Andrade, 2016; Moutinho; Dallari, 2019).

A redução das despesas públicas eleva a participação das famílias no custeio direto da sua saúde, aproximando o sistema de saúde brasileiro do modelo de cobertura universal atualmente defendido por organizações multilaterais como o Banco Mundial. Esse modelo pressupõe que a saúde seja responsabilidade das pessoas, famílias e empresas, cabendo ao Estado investir em ações básicas destinadas aos pobres e vulneráveis, discriminando os grupos de acordo com sua capacidade de pagamento (Araujo et al., [2019?]; Cebes, 2014; Heredia et al., 2015; Holst; Giovanella; Andrade, 2016).

Essas pressões e mudanças impostas ao sistema brasileiro podem indicar nova convergência com a Colômbia, dado que o Sistema General de Seguridad Social en Salud (SGSSS) é considerado uma experiência exemplar de cobertura universal (Hernández-Álvarez, 2014). Em sua reforma sanitária, a Colômbia sofreu influência direta do modelo conduzido pelo Banco Mundial e pelo Fundo Monetário Internacional, implicando na redução dos gastos sociais e na decadência dos serviços públicos (Santos; Ferreira, 2015; Vélez, 2016). O SGSSS institucionaliza dois regimes de afiliação da população: um contributivo (mediante remunerações laborais) e outro subsidiado, criado para assegurar a assistência à população não trabalhadora e abaixo da linha de pobreza (Almeida, 1999; Vélez, 2016). O modelo colombiano é ainda identificado como pluralismo estruturado, 
cuja característica principal é a transformação do Estado em modulador e articulador, deixando a prestação dos serviços a cargo de entidades eminentemente privadas: as entidades promotoras de saúde (EPS) operam como asseguradoras e administradoras, e as instituições prestadoras de serviço (IPS) são responsáveis por prover os serviços (Almeida, 1999; Londoño; Frenk, 1997).

Novamente, identifica-se a aproximação dos dois sistemas, tendo em vista o aumento do papel regulador do Estado brasileiro ao mesmo tempo que se intensifica a transferência da prestação dos serviços para entidades privadas, como as organizações sociais de saúde (Soares et al., 2016). Ressalta-se, no Brasil, a recente criação da Agência para o Desenvolvimento da Atenção Primária à Saúde, um serviço social autônomo de pessoa jurídica de direito privado sem fins lucrativos, com prerrogativa de contratar entidades públicas e privadas (Brasil, 2019) que passará a ter função central na prestação de serviços de atenção primária à saúde.

\section{As constituições e o novo papel do poder Judiciário}

A segunda característica do NCLA relaciona-se à ampliação do protagonismo do Judiciário, o qual adquiriu importantes prerrogativas em relação aos outros poderes, particularmente ao Executivo (Avritzer, 2017). Os juízes latino-americanos conquistaram maior blindagem política devido à expansão dos tempos de mandato e mudanças nos procedimentos de indicação e remoção (Ríos-Figueroa, 2011). Dessa forma, o aumento da independência do Judiciário se apresenta como um movimento relacionado a sistemas políticos e jurídicos que pretendem consolidar a democracia e a igualdade por meio de uma alta carga de direitos individuais, sociais e coletivos (Grijalva, 2017). Outro aspecto importante relacionado à expansão da atuação do poder Judiciário no NCLA é a ampliação do acesso à justiça pelos cidadãos por meio da criação de diversos instrumentos para adjudicação constitucional, como o amparo, a tutela, o habeas corpus, o habeas data, entre outros (Ríos-Figueroa, 2011). O acesso à justiça também envolve a observância ao devido processo legal e a accountability de cada ente estatal no que se refere ao tempo dos procedimentos judiciais e à transparência, condições que, segundo Pautassi (2018), estão diretamente relacionadas ao acesso aos serviços de saúde.

No Brasil, a CF/88 proveu o Judiciário com um alto nível de independência, tanto pelas amplas garantias constitucionais quanto pela consagração de uma capacidade efetiva de accountability dos outros poderes. A independência dos juízes foi ainda fortalecida pela garantia de mandato vitalício, salários altos e irredutíveis e proteção contra interferências em seu orçamento, carreiras e processos seletivos (Santiso, 2004). Também a ação civil pública foi instituída, promovendo proteção judicial em matéria de segurança ambiental, do consumidor, ocupacional e do direito à saúde em alguns casos (Courtis, 2006).

No caso colombiano, avanço relevante se refere à criação das ações de tutela, um procedimento judicial rápido, de baixo custo e que pode ser proposto por qualquer indivíduo a qualquer juiz, sem necessidade de advogado ou comprovação de interesse na demanda (Gargarella, 2013; Landau; López-Murcia, 2009; Pisarello, 2014; Uprimny, 2006). A constituição de 1991 também criou a Corte Constitucional, a qual se tornou umas das mais fortes do mundo (Landau; López-Murcia, 2009) e cuja principal função é proteger os direitos fundamentais, a supremacia e a integridade da Constituição, a partir do controle concentrado de constitucionalidade (Iturralde, 2013). O papel assumido pela Corte se deve ainda a fatores político-estruturais, como a crise de representação no país, a fraqueza dos movimentos sociais, dos partidos de oposição e da atuação do Legislativo, associada à concentração de poder no Executivo, em um movimento de reequilíbrio entre os poderes (Landau; López-Murcia, 2009; Uprimny, 2004, 2006; Uprimny; García-Villegas, 2002).

Vale enfatizar o novo entendimento de precedente judicial, que passou a assumir força de lei, sendo que as decisões da Corte se sobrepõem a regulamentos promulgados pelo Congresso Nacional (Iturralde, 2013). A Corte colombiana ainda vem limitando as ilegalidades cometidas pelo Executivo, como nos casos de abuso de poderes de 
emergência pelo presidente ${ }^{6}$ ou na substituição do poder Legislativo em vários momentos, fomentando e supervisionando a aplicação de políticas (Avritzer, 2017; Landau; López-Murcia, 2009; Uprimny, 2004, 2006). Para essa atuação, a Corte se baseia em grande medida na doutrina do "Estado de Coisas Inconstitucional", cuja ação abrange todos os cidadãos que se encontram expostos a condição considerada inconstitucional (Landau; LópezMurcia, 2009). ${ }^{7}$

No Brasil, por outro lado, o controle de constitucionalidade é misto, combinando o controle difuso, realizado por todos os juízes em casos concretos, e o concentrado/abstrato, exercido pelo Supremo Tribunal Federal (STF), aprimorado pela ampliação da propositura da Ação Direta de Inconstitucionalidade para diversos atores estatais e entidades da sociedade civil. O STF assumiu centralidade na função de guardar e uniformizar a interpretação da Constituição e revisão judicial em matéria constitucional, com força vinculante de suas decisões, em sede de Recurso Extraordinário (Avritzer, 2017; Avritzer; Marona, 2014). Observa-se, entretanto, uma resistência ao aspecto vinculante de decisões prévias, sendo que cada juiz se vê livre para interpretar a lei, mesmo em situações similares (Hoffmann; Bentes, 2008). Paralelamente há o desafio de lidar com interesses econômicos, políticos e midiáticos, os quais buscam moldar as decisões dos juízes (Grijalva, 2017). No caso brasileiro, há contradições na relação entre independência e accountability do próprio Judiciário, uma vez que não há meios de controle vertical da sua atuação, tornando-se um "poder acima do país e das leis” (Santiso, 2004, p. 126, tradução nossa).

\section{A expansão da participação popular no Brasil $e$ na Colômbia}

A expansão da participação popular é o principal avanço do NCLA, uma vez que significa o resgate da relação entre a soberania popular e o governo. Os pontos-chave desses mecanismos de participação são a legitimidade e o controle sobre o poder constituído, sem substituir a democracia representativa (Pastor; Dalmau, 2010). No Brasil, a participação na formulação e nos processos decisórios de políticas públicas foi ampliada em diversas partes da CF/88, desde o primeiro artigo (que trata da soberania popular) até artigos que versam sobre os direitos sociais e a organização dos poderes, por meio de plebiscito, referendo, iniciativa popular e geração de espaços deliberativos, como os conselhos de políticas públicas (Avritzer, 2017; Avritzer; Marona, 2014; Brasil, 1988). Além da democracia representativa, efetivada com o sufrágio universal, o regime político brasileiro incorpora a participação do cidadão por meio da sua presença e contribuição em espaços de decisão e também pelo controle social na implementação das políticas públicas. Na saúde, há espaços obrigatórios de participação e controle social nas três instâncias de gestão, como as conferências e os conselhos de saúde, envolvendo a representação paritária entre comunidade, órgãos e entidades governamentais. Há ainda as ouvidorias, as quais promovem a participação individual e complementam as estruturas coletivas (Campos; Salgado, 2018).

A Constituição da Colômbia apresenta o país como uma república participativa em seu primeiro artigo e traz, além dos instrumentos da democracia representativa, a democracia participativa, que inclui plebiscitos, referendos, iniciativas e consultas públicas, além de dois mecanismos que não existem no Brasil: ${ }^{8}$ a revogação de mandato (recall político) e o conselho aberto. O primeiro envolve uma votação popular para revogar o mandato de prefeitos ou governadores, enquanto o segundo pressupõe uma reunião pública em que a população pode participar diretamente para discutir assuntos de interesse da comunidade (Nárdiz, 2016). No sistema de saúde, a participação tem o objetivo de exercer o controle organizativo e de qualidade dos serviços, podendo ser individual

6 A declaração de estado de exceção (estado de sítio anteriormente à Constituição de 1991) foi uma medida tradicional na Colômbia, que permaneceu nesse estado entre 1949 e 1991 (Uprimny, 2004).

7 O Estado de Coisas Inconstitucional é amplamente utilizado nos casos que envolvem prisioneiros ou pessoas afetadas e deslocadas por conflitos armados (Landau; López-Murcia, 2009).

8 Está em tramitação no Senado brasileiro, desde 2015, a Proposta de Emenda à Constituição nº 21/2015, a qual cria o Direito de Revogação e o Veto Popular. 
ou coletiva, comunitária ou institucional (DelgadoGallego; Vázquez-Navarrete, 20o6).

A plena participação popular nos dois países, entretanto, enfrenta desafios relacionados à ausência de informações adequadas e tempestivas, à apatia e à desmotivação política de parte da população, além de assimetrias nos processos de representação ocasionadas pelas desigualdades socioeconômicas (Campos; Salgado, 2018; Delgado-Gallego; VázquezNavarrete, 2006). Na Colômbia, a participação é avaliada como muito aquém da ideal, podendo-se citar como causas a compra de votos, a influência política de atores econômicos e o hiperpresidencialismo (Nárdiz, 2016), desafios também observados na realidade brasileira. Quanto ao direito à saúde no Brasil, há ainda o controle dos conselhos pelos gestores, o que contraria a previsão legal de que tais órgãos colegiados deveriam ser hierarquicamente superiores (Campos; Salgado, 2018), e na Colômbia há o receio de represálias e da perda do acesso aos serviços (Delgado-Gallego; Vázquez-Navarrete, 2006).

\section{O novo constitucionalismo latino- americano e a judicialização da saúde no Brasil e na Colômbia}

Nas seções anteriores foram discutidas as dimensões do NCLA, tendo em vista suas diversas correntes teóricas. Há um consenso em torno das principais características das novas constituições da região, como o incremento das formas de participação democrática e a inserção e o reconhecimento de uma gama de direitos fundamentais e sociais, incluindo o direito à saúde. Destaca-se o fortalecimento do poder Judiciário a partir da ampliação de suas prerrogativas de atuação e das formas de acesso à justiça, mas com a manutenção do hiperpresidencialismo e da concentração vertical de poder.

Por outro lado, as mesmas constituições que trazem uma ampla carta de direitos não conseguiram enfrentar as pressões de políticas econômicas orientadas pelo mercado (Gargarella, 2013; Pisarello, 2014), sofrendo emendas voltadas para a transferência de recursos e competências para a iniciativa privada, redução do Estado, privatização, entre outras, o que enfraqueceu e inviabilizou políticas sociais e a efetivação dos direitos garantidos (Grijalva, 2017). Na Colômbia houve o abrandamento da coalizão política responsável pelo caráter progressivo da Carta de 1991, associado às políticas econômicas implementadas no governo Gaviria (1990-1994) e à mudança na Constituição realizada pelo presidente Pastrana (1998-2002) a fim de proteger investimentos estrangeiros (Pisarello, 2012, 2014; Uprimny, 2006). No Brasil, além da revisão constitucional de 1993, o governo de Fernando Henrique Cardoso (1995-2003) enviou 35 propostas de emenda constitucional para facilitar privatizações (Pisarello, 2012, 2014).

Dessa forma, diante da relação contraditória presente nos novos textos constitucionais e as políticas priorizadas no Brasil e na Colômbia, propõe-se um debate que abarque essas variáveis na discussão da judicialização da saúde nos dois países (Figura 1). Em outras palavras, o direito à saúde, que poderia ser concretizado por políticas efetivas, é relegado a segundo plano com a priorização de políticas econômicas de austeridade e orientadas pelo mercado, em paralelo ao fortalecimento da iniciativa privada na assistência à saúde e outros desafios apresentados pelos sistemas sanitários. Emerge, assim, o protagonismo do Judiciário, fortalecido pelas novas constituições, como o poder estatal capaz de concretizar um direito previsto, porém marginalizado. Esse cenário descreve condicionantes fundamentais para explicar o aumento progressivo de ações judiciais envolvendo prestações de serviços de saúde no Brasil e na Colômbia: o reconhecimento do direito à saúde, a não efetivação desse direito e o fortalecimento e a receptividade do Judiciário para protegê-lo.

O respeito ao texto constitucional também impõe à justiça ordinária pautas interpretativas dos direitos e princípios constitucionais (Grijalva, 2017). Gargarella (2006) defende que em democracias deliberativas os juízes não deveriam permanecer passivos com o não cumprimento dos direitos sociais. Para o autor, o envolvimento do Judiciário enriquece o debate democrático, uma vez que ocupa a função estratégica de receber as demandas daqueles marginalizados ou afetados pelas decisões dos outros poderes. 
Figura I - Esquema explicativo da discussão da judicialização da saúde a partir das bases do novo constitucionalismo latino-americano

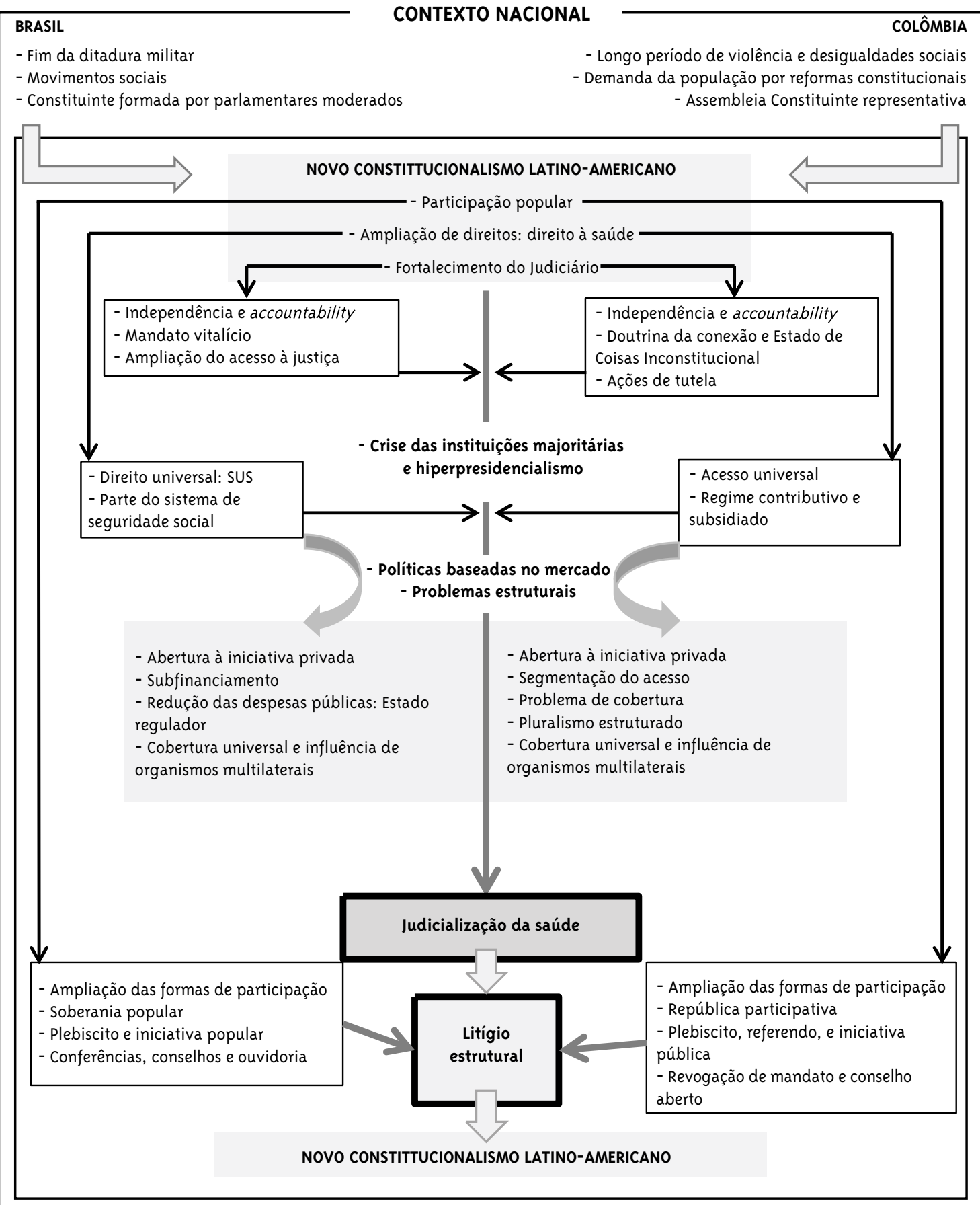

Com vistas a dimensionar esse fenômeno, podemse citar dados recentes que revelam a realidade dos países. Em 2018, as ações em saúde na Colômbia representaram 34,21\% (n=207.734) do total de tutelas, o que significou uma cifra de 41,68 ações por 10 mil habitantes (Colômbia, 2019). No caso do Brasil, 
dados do CNJ revelam ampliação do volume de ações nos últimos anos, sendo observado um aumento de $25,32 \%$ de 2018 para $2019^{9}(n=2.228 .531),{ }^{10}$ a uma taxa 106,39 ações em saúde por 10 mil habitantes ${ }^{11}$ (Schulze, 2019).

Em relação aos tipos de pedidos, na Colômbia (2019) os mais frequentes foram por tratamentos $(24,93 \%)$, diferentemente do Brasil, onde a principal demanda foi por medicamentos no SUS $(24,43 \%)$ (Schulze, 2019). Quanto aos réus, as EPS foram as entidades mais demandadas na Colômbia $(85,41 \%)$, sendo que a maioria das ações se referia a prestações incluídas no sistema pelo Plano de Benefícios de Saúde. O regime subsidiado apresentou maior volume de ações (49,45\%), o que levanta a hipótese de que as EPS podem estar priorizando o atendimento dos filiados ao regime contributivo (Colômbia, 2019). No Brasil, em um estudo encomendado pelo CNJ com amostra de 164.587 ações, foi observada maior litigância na saúde suplementar, principalmente na primeira instância. Além disso, estados com elevada cobertura de planos privados de saúde foram os que apresentaram o maior número de processos judiciais (Azevedo; Aith, 2019).

Em relação à atuação das cortes supremas, a Corte Constitucional colombiana vem utilizando as tutelas no amparo dos direitos sociais, inclusive do direito à saúde. Apesar de a Constituição de 1991 restringir o uso da ação de tutela para direitos civis e políticos, a Corte passou a utilizar a doutrina da conexão para proteger os direitos sociais de forma indireta, ou seja, para que um direito social seja resguardado pelo Judiciário, sua não efetivação deve implicar na violação de um direito fundamental diretamente aplicável, como o direito à vida, à integridade física ou à dignidade humana (Uprimny, 2006). Em 2008, a Corte emitiu a sentença T-76o, que buscou corrigir falhas estruturais do sistema de saúde colombiano a partir de ações de tutela individuais acumuladas. Entre as ordens emitidas estão a unificação dos planos de benefícios entre os regimes, a garantia de financiamento adequado, o monitoramento pelos usuários e a prestação de contas, pelo governo, sobre os avanços obtidos (Cano, 2015). A partir de então, a jurisprudência da Corte culminou com a publicação da Lei Estatutária do Direito à Saúde (Lei n ${ }^{0}$ 1.751/2015), em que esse direito foi consagrado como fundamental, portanto passível de ser exigido diretamente pela tutela (Colômbia, 2019).

No Brasil, o STF iniciou um movimento para garantir maior legitimidade à sua atuação convocando audiências públicas, como a realizada em 2009, relacionada às ações e serviços de saúde. A partir das questões discutidas, o Tribunal julgou um caso envolvendo o direito à saúde no estado de Pernambuco, ${ }^{12}$ cujos resultados vêm influenciando os julgados na matéria. Entre os argumentos dos magistrados encontra-se a visão de que a Corte não pode se eximir diante da não efetivação do direito à saúde pelos órgãos competentes, e que ao agir nesse sentido está cumprindo sua missão e honrando a Constituição (Maggio; Dallari, 2017). Maggio e Dallari (2017, p. 74) enfatizam que, apesar de certas análises considerarem que o julgamento ultrapassou o conteúdo do caso, houve "fortalecimento constitucional-sanitário do direito à saúde" e mudanças na atuação do Executivo e do Legislativo.

Gloppen (2006) e Uprimny (2006) ressaltam que um papel ativo das cortes no âmbito dos direitos sociais levanta uma série de dilemas e críticas, como a afronta à separação de poderes; a incapacidade técnica dos juízes e sua ilegitimidade de se sobrepor às decisões dos outros poderes eleitos, representantes dos cidadãos; a interferência na alocação de recursos; e o esvaziamento dos movimentos sociais, os quais deslocariam suas demandas para o poder Judiciário. Gloppen (2006), entretanto, afirma que, não obstante o fortalecimento de direitos pelas cortes ser potencialmente custoso,

9 Cálculo do aumento percentual anual realizado a partir dos dados apresentados por Schulze (2019).

10 Segundo Schulze (2019), foram acrescidas duas novas categorias de pesquisa: fornecimento de medicamento (planos de saúde) e taxa de saúde suplementar (tributário).

11 Cálculo do volume de ações por 10 mil habitantes realizado a partir de Schulze (2019) e dos dados demográficos disponibilizados pela Comisión Económica para América Latina y el Caribe (Cepal) em <https://bit.ly/2YApjNA $>$.

12 Ação civil pública que visou a tomada de providências administrativas pelo município de Petrolina para melhorar o atendimento aos usuários do SUS, pelo Hospital Dom Malan (Maggio; Dallari, 2017). 
tanto em nível econômico quanto em termos do espaço democrático, a necessidade de priorizar as questões mais vitais é reforçada.

Uprimny (2006), ao focar no direito à saúde, destaca que se, de um lado, a intervenção judicial prejudica a equidade da assistência, a coerência das políticas e a sustentabilidade financeira do sistema, por outro, representa para os demandantes a satisfação das suas necessidades básicas e a melhoria da sua qualidade de vida. Essa análise não esgota o debate acerca da judicialização da saúde na perspectiva do papel assumido pelo poder Judiciário a partir das novas constituições do Brasil e da Colômbia. Há discussões sobre o potencial emancipatório e transformador das decisões judiciais, as quais se baseiam na ideia de que o poder progressista das decisões está na concretização da esperança depositada nos textos constitucionais, fazendo com que os atores sociais encontrem um catalisador para a mobilização política (Uprimny, 2006; Uprimny; García-Villegas, 2002).

O potencial de transformação social da atuação do Judiciário na judicialização dos direitos sociais está relacionado a diversas variáveis, como a capacidade dos juízes em dar efeito legal aos direitos demandados e a observância das decisões pelas autoridades, a disponibilidade de ajuda jurídica e barreiras de acesso à justiça, entre outras (Gloppen, 2006). Nessa seara, o acesso à justiça e a correção das desigualdades na saúde assumem grande relevância, dado que há diversos questionamentos quanto ao real papel transformador da judicialização. Conforme evidenciado no estudo do CNJ, o perfil das demandas judiciais analisadas parece corroborar a hipótese de que há assimetrias nas condições de acesso, além de eventuais efeitos de regressividade em relação à distribuição de recursos do sistema de saúde (Azevedo; Aith, 2019). Resultados similares foram encontrados na Colômbia (2019), onde as regiões mais desenvolvidas apresentaram maior volume de ações, provavelmente devido à facilidade de acesso à justiça, à oferta de serviços de saúde de alta tecnologia, à densidade populacional e ao nível cultural dessas localidades.

Todo esse debate em torno dos impactos e da capacidade das decisões judiciais em produzir mudanças sociais efetivas tem sido concentrado na defesa do litígio estrutural, um modelo de judicialização que ultrapassa a jurisdição individual, restrita ao caso concreto, e que tem o potencial de dar efeito coletivo aos resultados da ação judicial por meio de mudanças estruturais. Ao analisar o caso colombiano, Cano (2015) ressalta que o litígio estrutural é considerado exitoso quando a sentença, além de beneficiar os demandantes, promove mudanças estruturais (normativas ou de políticas públicas) que afetam um grande número de pessoas, principalmente as mais vulneráveis, com vistas a corrigir desigualdades, além de propiciar espaços de deliberação e motivar a mobilização social em torno do tema. Ademais, para se garantir o sucesso da judicialização, a decisão deve recair sobre a efetivação de políticas já existentes e não criar novas, devendo a execução da política ser acompanhada por organizações sociais. Nessa perspectiva, ao proferir a sentença T-76o/2008, a atuação da Corte Constitucional colombiana pode ser considerada apenas parcialmente exitosa, uma vez que não conseguiu promover a participação cidadã (Cano, 2015).

No caso brasileiro, Lima (2015) classifica o litígio estrutural como um tipo de litígio coletivo que afeta, de formas distintas, diversos grupo de pessoas, com interesses diferentes em relação ao objeto do processo. Esse litígio envolve mudanças no funcionamento de instituições estatais complexas, como os sistemas de saúde, e pressupõe que todos os interesses sejam representados de forma legítima e pluralizada, desde a obtenção de informações para a compreensão adequada do problema, das alternativas, oportunidades e soluções, até a consulta a cada legitimado coletivo sobre suas preocupações e aspirações. $O$ autor ainda ressalta que enquanto a participação processual dos grupos envolvidos não for concretizada, não será possível realizar modificações estruturais, pois, além de aspectos importantes só serem evidenciados no momento da implementação da sentença, a legitimidade e aceitação social da decisão interferem em sua efetividade (Lima, 2015).

A participação, portanto, é a questão central do litígio estrutural, tanto no caso colombiano 
quanto no brasileiro, o que representa o resgate dos princípios do novo constitucionalismo latinoamericano como fundamentos para se repensar a judicialização da saúde nos dois países, com vistas à plena efetivação do direito à saúde (Figura 1). A Colômbia está mais à frente do Brasil na busca por soluções estruturais, tendo em vista a atuação da Corte Constitucional no sentido de dar efeitos coletivos às tutelas. O Judiciário brasileiro, por outro lado, é tido como sendo mais resistente a ações coletivas (Hoffmann; Bentes, 2oo8), panorama que vem se modificando nos últimos anos (Azevedo; Aith, 2019; Lima, 2015).

Vale ressaltar que a judicialização da política no Brasil tem importância reconhecida para amparar direitos e racionalizar a administração pública, sendo parte do jogo democrático e lócus favorável ao exercício da cidadania (Vianna et al., 1999). No entanto, a mudança social e as reformas estruturais só serão exitosas se a judicialização ultrapassar as ordens judiciais pontuais e envolver todas as pessoas impactadas pelas decisões, e não somente o autor, o juiz e o réu (Lima, 2015).

\section{Considerações finais}

A judicialização, segundo a perspectiva do NCLA, é parte do movimento pela garantia do direito à saúde, associada à maior força e autonomia do poder Judiciário para proteger esse direito que, no contexto da região, vem sendo ameaçado por questões estruturais e políticas econômicas desfavoráveis. Embora a judicialização seja um fenômeno relevante tanto na Colômbia quanto no Brasil, os dados apresentados revelam que neste a realidade é ainda mais preocupante, evidenciando a necessidade de se repensar o modelo de litigância para outro mais justo, que atinja a população coletivamente e que promova transformações estruturais. Não se trata de negar a ação individual como mecanismo legítimo, principalmente por se tratar de um direito de todo cidadão e por evidenciar questões que precisam ser discutidas e priorizadas, mas de se tomar novos caminhos para que a judicialização seja realmente utilizada como uma forma de se efetivar o direito à saúde.
Paralelamente, ressalta-se a importância de discutir o papel do Judiciário nesse processo, o qual, ainda que seja parte fundamental no amparo do direito à saúde, tem contribuído para a sustentação de interesses individuais e privados ao não focar questões estruturantes, ao interferir acriticamente nos orçamentos em saúde ou ao ceder às pressões majoritárias de poder. A participação social é o princípio basilar, representando o eixo democrático do NCLA e a luta permanente dos povos da região.

Vislumbra-se com este estudo uma agenda de pesquisa para aprofundamento da análise, tendo em vista as mudanças impostas ao sistema de saúde brasileiro, o qual vem se aproximando do modelo colombiano. Os sistemas jurídicos, por outro lado, apesar das convergências trazidas pelo NCLA, apresentam diferenças marcantes, que fazem com que a Colômbia, na perspectiva do fenômeno da judicialização, esteja mais avançada em termos da potencialização de efeitos estruturais e emancipatórios.

\section{Referências}

ALMEIDA, C. M. Reforma do Estado e reforma de sistemas de saúde: experiências internacionais e tendências de mudança. Ciência e Saúde Coletiva, Rio de Janeiro, v. 4, n. 2, p. 263-286, 1999.

ANDRADE, E. I. G. et al. A judicialização da saúde e a política nacional de assistência farmacêutica no Brasil: gestão da clínica e medicalização da justiça. Revista Médica de Minas Gerais, Belo Horizonte, v. 18, p. S46-S5o, 2008. Suplemento 4.

ARAUJO, E. C. et al. (Org.). Propostas de reformas do Sistema Único de Saúde Brasileiro. Washington, DC: Banco Mundial, [2019?]. Disponível em: <https://bit.ly/2Uw2usZ>. Acesso em: 18 jan. 2020.

AVRITZER, L. O novo constitucionalismo latino-americano: uma abordagem política. In: AVRITZER, L. et al. (Org.). O constitucionalismo democrático latino-americano em debate:

soberania, separação de poderes e sistema de direitos. Belo Horizonte: Autêntica, 2017. p. 19-42.

AVRITZER, L.; MARONA, M. C. Judicialização da política no Brasil: ver além do constitucionalismo 
liberal para ver melhor. Revista Brasileira de Ciência Política, Brasília, DF, n. 15, p. 69-94, 2014.

AZEVEDO, P. F.; AITH, F. M. A. (Coord.). Judicialização da saúde no Brasil: perfil das demandas, causas e propostas de solução. Brasília, DF: Insper: CNJ, 2019.

BRAGATO, F. F.; CASTILHO, N. M. A importância do pós-colonialismo e dos estudos descoloniais na análise do novo constitucionalismo latinoamericano. In: VAL, E. M.; BELLO, E. (Org.). O pensamento pós e descolonial no novo constitucionalismo latino-americano.

Caxias do Sul: Educs, 2014. p. 11-25.

BRASIL. Constituição da República Federativa do Brasil: 1988. Brasília, DF: Senado Federal, 1988.

BRASIL. Lei $n^{0} 13.958$, de 18 de dezembro de 2019. Institui o Programa Médicos pelo Brasil, no âmbito da atenção primária à saúde no Sistema Único de Saúde (SUS), e autoriza o Poder Executivo federal a instituir serviço social autônomo denominado Agência para o Desenvolvimento da Atenção Primária à Saúde (Adaps). Diário Oficial da União. Brasília, DF, 19 dez. 2019.

BULCOURF, P. A.; CARDOZO, N. D. ¿Por qué comparar políticas públicas? Política Comparada, Buenos Aires, n. 3, p. 1-49, 2008.

CAMPOS, T. L. C.; SALGADO, V. A. B. A diretriz constitucional de participação social no SUS. In: SANTOS, A. O.; LOPES, L. T. (Org.). Coletânea direito à saúde: institucionalização. Brasília, DF: Conass, 2018. v. 1. p. 44-54.

CAMPOS NETO, O. H.; GONÇALVES, L. A. O.; ANDRADE, E. I. G. A judicialização da saúde na percepção de médicos prescritores. Interface: Comunicação, Saúde, Educação, Botucatu, v. 22, n. 64, p. 165-176, 2018.

CANO, L. F. El litigio estructural en salud: un estudio comparado con base en casos de Sudáfrica, Argentina, India y Colombia. Revista Facultad Nacional de Salud Pública, Medellín, v. 33, n. 1, p. 111-120, 2015.

CEBES - CENTRO BRASILEIRO DE ESTUDOS DE SAÚDE. Por que defender o Sistema Único de Saúde? Diferenças entre direito universal e cobertura universal de saúde. Rio de Janeiro, 2014.

COLÔMBIA. Constitución política de Colombia.

Bogotá, DC: Asamblea Nacional Constituyente, 1991.

COLÔMBIA. Defensoría del Pueblo. La tutela y los derechos a la salud y a la seguridad social. Bogotá, DC, 2019.

COSTA, A. M.; RIZZOTTO, M. L. F. Uma aposta pelo Brasil. Saúde em Debate, Rio de Janeiro, v. 41, n. 113, p. 345-348, 2017.

COURTIS, C. Judicial enforcement of social rights: perspectives from Latin America. In: GARGARELLA, R.; DOMINGO, P.; ROUX, T. (Ed.). Courts and social transformation in new democracies: an institutional voice for the poor? Hampshire: Ashgate, 2006. p. 169-184.

DELGADO-GALLEGO, M. E.; VÁZQUEZ-NAVARRETE, L. Barreras y oportunidades para la participación social en salud en Colombia: percepciones de los actores principales. Revista de Salud Pública, Bogotá, DC, v. 8, n. 2, p. 128-140, 2006.

DÍAZ, C. G. Los derechos económicos y sociales en el nuevo constitucionalismo latinoamericano. In: CORTE CONSTITUCIONAL DEL ECUADOR PARA EL PERÍODO DE TRANSICIÓN. El nuevo constitucionalismo en América Latina. Quito: Corte Constitucional del Ecuador, 2010. p. 67-79.

EVANS, P. B.; RUESCHEMEYER, D.; SKOCPOL, $\mathrm{T}$. On the road toward a more adequate understanding of the State. In: EVANS, P. B.; RUESCHEMEYER, D.; SKOCPOL, T. (Ed.). Bringing the state back in. Nova York: Cambridge University Press, 1985. p. 347-366.

FERRAZ, O. L M. Brazil: health inequalities, rights, and courts: the social impact of the judicialization of health. In: YAMIN, A. E.; GLOPPEN, S. (Ed.) Litigating health rights: can courts bring more justice to health? Cambridge: Harvard University Press, 2011. p. 76-102. FLEURY, S. Judicialização pode salvar o SUS. Saúde em Debate, Rio de Janeiro, v. 36, n. 93, p. 159-162, 2012. 
GARBOIS, J. A.; VARGAS, L. A.; CUNHA, F. T. S. O direito à saúde na Estratégia Saúde da Família: uma reflexão necessária. Physis: Revista de Saúde Coletiva, Rio de Janeiro, v. 18, n. 1, p. 27-44, 2008.

GARGARELLA, R. Theories of democracy, the judiciary and social rights. In: GARGARELLA, R.; DOMINGO, P.; ROUX, T. (Ed.). Courts and social transformation in new democracies: an institutional voice for the poor? Hampshire: Ashgate, 2006. p. 13-34.

GARGARELLA, R. Latin American constitutionalism: 1810-2010: the engine room of the constitution. Nova York: Oxford University Press, 2013.

GARGARELLA, R. Presidencialismo versus direitos no novo constitucionalismo latino-americano. In: AVRITZER, L. et al. (Org.). O constitucionalismo democrático latino-americano em debate: soberania, separação de poderes e sistema de direitos. Belo Horizonte: Autêntica, 2017. p. 43-75.

GARGARELLA, R.; COURTIS, C. El nuevo constitucionalismo latinoamericano: promesas e interrogantes. Santiago de Chile: Naciones Unidas, 2009. (Serie Políticas Sociales, 153).

GLOPPEN, S. Courts and social transformation: an analytical framework. In: GARGARELLA, R.; DOMINGO, P.; ROUX, T. (Ed.). Courts and social transformation in new democracies: an institutional voice for the poor? Hampshire: Ashgate, 2006. p. 35-59.

GOMES, F. F. C. et al. Acesso aos procedimentos de média e alta complexidade no Sistema Único de Saúde: uma questão de judicialização. Cadernos de Saúde Pública, Rio de Janeiro, v. 3o, n. 1, p. 31-43, 2014.

GRIJALVA, A. Novo constitucionalismo, ativismo e independência judicial. In: AVRITZER, L. et al. (Org.). O constitucionalismo democrático latinoamericano em debate: soberania, separação de poderes e sistema de direitos. Belo Horizonte: Autêntica, 2017. p. 119-134.

HEREDIA, N. et al. The right to health: what model for Latin America? Lancet, Londres, v. 385 , n. 9975, p. e34-e37, 2015.
HERNÁNDEZ-ÁLVAREZ, M. Colombia: modelo de "cobertura universal en salud". Cebes, Rio de Janeiro, 3 dez. 2014. Disponível em: <https://bit. ly/2MNRinw>. Acesso em: 15 jul. 2017.

HOFFMANN, F. F.; BENTES, F. R. N. M.

Accountability for social and economic rights in Brazil. In: GAURI, V.; BRINKS, D. M. (Ed.). Courting social justice: judicial enforcement of social and economic rights in the developing world. Nova York: Cambridge University Press, 2008. p. 100-145.

HOLST, J.; GIOVANELLA, L.; ANDRADE, G. C. L. Por que não instituir copagamento no Sistema Único de Saúde: efeitos nocivos para o acesso a serviços e a saúde dos cidadãos. Saúde em Debate, Rio de Janeiro, v. 4o, p. 213-226, 2016. Número especial.

ITURRALDE, M. Access to constitutional justice in Colombia. In: MALDONADO, D. B. (Ed.). Constitutionalism of the global South: the activist tribunals of India, South Africa, and Colombia. Nova York: Cambridge University Press, 2013. p. 361-402.

LANDAU, D.; LÓPEZ-MURCIA, J. D. Political institutions and judicial role: an approach in context, the case of the Colombian Constitutional Court. Vniversitas, Bogotá, DC, n. 119, p. 55-92, 2009.

LIMA, E. V. D. O devido processo legal coletivo: representação, participação e efetividade da tutela jurisdicional. 2015. Tese (Doutorado em Direito) Universidade Federal do Paraná, Curitiba, 2015.

LONDOÑO, J.-L.; FRENK, J. Pluralismo estructurado: hacia un modelo innovador para la reforma de los sistemas de salud en América Latina. Nova York: Banco Interamericano de Desarrollo, 1997. (Documento de Trabajo 353)

MACHADO, F. R. S.; DAIN, S. A audiência pública da saúde: questões para a judicialização e para a gestão de saúde no Brasil. Revista de Administração Pública, Rio de Janeiro, v. 46, n. 4, p. 1017-1036, 2012.

MAGGIO, M. P.; DALLARI, S. G. A efetivação jurídico-política do direito à saúde no Supremo Tribunal Federal: a referência paradigmática da SL 47-AGR/PE. Revista de Direito Sanitário, São Paulo, v. 17, n. 3, p. 58-76, 2017. 
MOUTINHO, D. V.; DALLARI, S. G. Financiamento do direito à saúde e novo regime fiscal: a inconstitucionalidade do artigo 110 do Ato das Disposições Constitucionais Transitórias. Revista de Direito Sanitário, São Paulo, v. 19, n. 3, p. 68-90, 2019.

NÁRDIZ, A. R. Participación ciudadana e interpretación de la constitución: análisis de la jurisprudencia de la Corte Constitucional colombiana en materia de democracia participativa. Revista IUS, Puebla, v. 10, n. 37, p. 171-192, 2016.

PASTOR, R. V.; DALMAU, R. M. Aspectos generales del nuevo constitucionalismo latinoamericano. In: CORTE CONSTITUCIONAL DEL ECUADOR PARA EL PERÍODO DE TRANSICIÓN. El nuevo constitucionalismo en América Latina. Quito: Corte Constitucional del Ecuador, 2010. p. 9-43.

PAULA, P. A. B. et al. Política de medicamentos: da universalidade de direitos aos limites da operacionalidade. Physis: Revista de Saúde Coletiva, Rio de Janeiro, v. 19, n. 4, p. 1111-1125, 2009.

PAUTASSI, L. Access to justice in health matters: an analysis based on the monitoring mechanisms of the Inter-American System. Health and Human Rights, Boston, v. 20, n. 1, p. 185-197, 2018.

PISARELLO, G. El constitucionalismo neoliberal y su crisis: entre la stasis y la regeneración democrática. In: PISARELLO, G. Un largo termidor: historia y crítica del constitucionalismo antidemocrático. Quito: Corte Constitucional para el Período de Transición, 2012. p. 165-205.

PISARELLO, G. Los nuevos procesos constituyentes democratizadores. In: PISARELLO, G. Procesos constituyentes: caminos para la ruptura democrática. Madri: Trotta, 2014. p. 107-134.

RÍOS-FIGUEROA, J. Institutions for constitutional justice in Latin America. In: HELMKE, G.; RÍOSFIGUEROA, J. (Ed.). Courts in Latin America. Nova York: Cambridge University Press, 2011. p. 27-54.

SANTISO, C. Economic reform and judicial governance in Brazil: balancing independence with accountability. In: GLOPPEN, S.; GARGARELLA, R.; SKAAR, E. (Ed.). Democratization and the judiciary: the accountability function of courts in new democracies. Londres: Frank Cass, 2004. p. 117-131.

SANTOS, V. J. C. F.; FERREIRA, F. P. M.

Universalização da saúde: propostas e trajetórias dos sistemas de saúde do Brasil e Colômbia.

Economia e Políticas Públicas, Montes Claros, v. 3, n. 1, p. 7-29, 2015.

SCHULZE, C. J. Números de 2019 da judicialização da saúde no Brasil. Empório do Direito, São Paulo, 2 set. 2019. Disponível em: <https://bit.ly/2XR1Zf2>. Acesso em: 6 set. 2019.

SILVA, R. C. C. Possibilidades de atuação das ouvidorias públicas de saúde: um estudo de caso das demandas do Ministério Público em município de pequeno porte. Revista de Direito Sanitário, São Paulo, v. 14, n. 1, p. 6o-76, 2013.

SOARES, G. B. et al. Organizações sociais de saúde (OSS): privatização da gestão de serviços de saúde ou solução gerencial para o sus? Gestão \& Saúde, Brasília, DF, v. 7, n. 2, p. 828-850, 2016.

STRECK, L. L. Entre o ativismo e a judicialização da política: a difícil concretização do direito fundamental a uma decisão judicial constitucionalmente adequada. Espaço Jurídico Journal of Law, Joaçaba, v. 17, n. 3, p. 721-732, 2016.

UPRIMNY, R. The constitutional court and control of presidential extraordinary powers in Colombia. In: GLOPPEN, S.; GARGARELLA, R.; SKAAR, E. (Ed.). Democratization and the judiciary: the accountability function of courts in new democracies. Londres: Frank Cass, 2004. p. 46-69.

UPRIMNY, R. The enforcement of social rights by the Colombian Constitutional Court: cases and debates. In: GARGARELLA, R.; DOMINGO, P.; ROUX, T. (Ed.). Courts and social transformation in new democracies: an institutional voice for the poor? Hampshire: Ashgate, 2006. p. 127-151.

UPRIMNY, R.; GARCÍA-VILLEGAS, M. Tribunal Constitucional e emancipação social na Colômbia. In: SANTOS, B. S. (Org.). Democratizar a democracia: os caminhos da democracia participativa. Rio de Janeiro: Civilização Brasileira, 2002. p. 297-339. 
VÉLEZ, M. La salud en Colombia: pasado, presente y futuro de un sistema en crisis. Bogotá, DC:

Debate, 2016.

VIANNA, L. W. et al. A judicialização da política e das relações sociais no Brasil. Rio de Janeiro:

Revan, 1999.

VIEIRA, F. S. Ações judiciais e direito à saúde: reflexão sobre a observância aos princípios do
SUS. Revista de Saúde Pública, São Paulo, v. 42, n. 2, p. 365-369, 2008.

WOLKMER, A. C. Pluralismo e crítica do constitucionalismo na América Latina. In: SIMPÓSIO NACIONAL DE DIREITO CONSTITUCIONAL, 9., 2010, Curitiba. Anais... Curitiba: Academia Brasileira de Direito Constitucional, 2010. p. 143-155.

\section{Agradecimentos}

À professora Marjorie Corrêa Marona e aos pareceristas pelas contribuições valiosas para o artigo.

\section{Contribuição dos autores}

d'Ávila coletou e analisou as informações. Andrade e Aith participaram da revisão bibliográfica. Todos os autores contribuíram significativamente na elaboração do artigo e na revisão crítica do conteúdo e aprovaram a versão final do manuscrito.

Recebido: $11 / 09 / 2019$

Reapresentado: 23/04/2020

Aprovado: 25/05/2020 